\title{
Associations between spontaneous meal initiations and blood glucose dynamics in overweight men in negative energy balance
}

\author{
Eva M. R. Kovacs*, Margriet S. Westerterp-Plantenga, Wim H. M. Saris, Kathleen J. Melanson, \\ Ine Goossens, Peter Geurten and Fred Brouns \\ Department of Human Biology, Maastricht University, The Netherlands \\ (Received 19 April 2001 - Revised 30 July 2001 - Accepted 24 August 2001)
}

\begin{abstract}
The aim of the present study was to investigate associations between spontaneous meal initiations and blood glucose dynamics in overweight male subjects in negative energy balance. In a randomized crossover design, fifteen overweight male subjects (BMI 28.6 (SD $1.8 \mathrm{~kg} / \mathrm{m}^{2}$ ) participated in three treatments, each of which consisted of 2 weeks consuming a low-energy diet followed by a test of voluntary food ingestion in the absence of time-related cues. The low-energy diet consisted of three daily meals $(947 \mathrm{~kJ})$ which were either semi-solid with or without $2.5 \mathrm{~g}$ guar gum, or solid, and a dinner of subject's own choice. During the time-blinded test, on the first, second, and third meal initiation subjects ingested a low-energy meal corresponding to that used during the preceding weeks. Changes in blood glucose were monitored on-line. Associations between spontaneous meal initiations and blood glucose dynamics were determined using the $\chi^{2}$ test. No difference was found between treatments in the occurrence of postabsorptive and postprandial declines in blood glucose or in associations between meal initiations and blood glucose dynamics. Postprandial dynamic blood glucose declines were associated with meal initiation $\left(\chi^{2} 26 \cdot 8, P<0 \cdot 001\right)$, but postabsorptive and postprandial transient declines were not. In overweight subjects, the usual association between transient declines and spontaneous meal initiation was completely absent in negative energy balance.
\end{abstract}

Glucostatic theory: Food intake regulation: Low-energy diet: Blood glucose pattern

Carbohydrate metabolism has been proposed to be fundamental in the regulation of food intake, due to its limited storage, high turnover rate, immediate and tight regulation, and its critical role as fuel source for the central nervous system (Mayer, 1953; Flatt, 1981). The glucostatic hypothesis postulates that reduced glucose utilization in critical brain regions leads to perception and expression of hunger in animals (Mayer, 1953; Steffens, 1970; Louis-Sylvestre \& Le Magnen, 1980; Campfield et al. 1985; Flatt, 1996) and human subjects (Campfield et al. 1996; Melanson et al. 1999a,c). As a consequence, changes reflected by declines in blood glucose have been suggested to play a role in short-term food intake regulation and may depend on carbohydrate availability. Transient blood glucose declines have been shown to coincide with increased hunger and to precede and signal meal initiation in free-feeding lean, obese and diabetic rats (Louis-Sylvestre \& Le Magnen, 1980; Campfield et al. 1985; Campfield \& Smith, 1986, 1990a,b; Smith \& Campfield, 1993) and in fasting human subjects (Campfield et al. 1996; Melanson et al. 1999a,c). In the postprandial state, transient and dynamic blood glucose declines have been shown to predict spontaneous meal initiation in time-blinded human subjects (Melanson et al. $1999 a, c)$. Previously, a major limitation in the investigation of the role of blood glucose in hunger had been the use of discrete blood sampling (Mayer, 1953; LouisSylvestre \& Le Magnen, 1980; Campfield \& Smith, 1986, 1990a,b; Pollack et al. 1989; Van Itallie, 1990; Smith \& Campfield, 1993). The application of contemporary technology for continuous monitoring of blood glucose concentration (Campfield et al. 1985, 1996; Melanson et al. 1999a,b,c) allows testing of the hypothesis that hunger and meal initiations in human subjects can be related to patterns in blood glucose concentration. Continuous blood glucose monitoring has been applied in human subjects to study meal initiation during the morning after an overnight fast (Campfield et al. 1996), as well as during a full day in lean males, in energy balance (Melanson et al. 1999a,b,c).

In a larger study we investigated the effects of guar gum addition to a low-energy semi-solid meal on appetite in 
relation to blood glucose and other blood variables, in overweight male subjects who were on a low-energy diet (Kovacs et al. 2001; EMR Kovacs, MS WesterterpPlantenga, WHM Saris, KJ Melanson, I Goossens, P Geurten and F Brouns, unpublished results). We found that guar gum addition to a semi-solid meal prevented an increase in appetite, hunger and desire to eat, while this increase was present in the unsupplemented semi-solid meal and in a low-energy solid meal. In addition, similarly to the solid meal, the semi-solid meal with guar gum resulted in a more moderate change in blood glucose compared to the unsupplemented semi-solid meal. Because of these different effects of meal type on appetite and blood glucose variables, we wondered whether in these subjects in a negative energy balance food intake would still be related to the same physiological variables, e.g. blood glucose patterns, as in lean males in energy balance. Therefore, the aim of the present study was to investigate associations between spontaneous meal initiations and blood glucose dynamics in overweight male subjects, after a 2-week low-energy diet, consisting of three meals per $\mathrm{d}$, which were either semi-solid (with or without $2.5 \mathrm{~g}$ guar gum) or solid, and a dinner of the subject's own choice.

\section{Subjects and methods}

\section{Subjects}

Fifteen overweight male subjects participated in this study. The subjects were a subsample of a larger study that is described in Kovacs et al. (2001; EMR Kovacs, MS Westerterp-Plantenga, WHM Saris, KJ Melanson, I Goossens, P Geurten and F Brouns, unpublished results). Selection for this study took place following health criteria (fasting blood glucose $<6.2 \mathrm{mmol} / \mathrm{l}$, no diabetes, no cardiovascular diseases, and no medical treatment) and body weight criteria (BMI $25-30 \mathrm{~kg} / \mathrm{m}^{2}$ ). Baseline characteristics of the subjects are presented in Table 1 . The nature and risks of the experimental procedure were explained to the subjects, and all subjects gave their written informed

Table 1. Subjects' characteristics at baseline (Mean values, standard deviations and ranges for fifteen men)

\begin{tabular}{|c|c|c|c|}
\hline & Mean & SD & Range \\
\hline Age (years) & 43.7 & $9 \cdot 3$ & $29-56$ \\
\hline Height (m) & 1.77 & 0.06 & $1.65-1.88$ \\
\hline Weight (kg) & $89 \cdot 2$ & $7 \cdot 7$ & $79 \cdot 6-102 \cdot 7$ \\
\hline BMI $\left(\mathrm{kg} / \mathrm{m}^{2}\right)$ & 28.6 & 1.8 & $25 \cdot 9-32 \cdot 4$ \\
\hline Waist circumference $(\mathrm{cm})$ & 98 & 6 & $91-108$ \\
\hline Hip circumference $(\mathrm{cm})$ & 104 & 5 & $96-112$ \\
\hline Waist:hip ratio & 0.94 & 0.04 & $0.85-1.01$ \\
\hline Body fat $(\%)$ & $30 \cdot 9$ & $1 \cdot 1$ & $23 \cdot 3-38 \cdot 5$ \\
\hline Systolic blood pressure $(\mathrm{mmHg})$ & 149 & 23 & $116-206$ \\
\hline Diastolic blood pressure $(\mathrm{mmHg})$ & 91 & 11 & $77-106$ \\
\hline Blood glucose $(\mathrm{mmol} / \mathrm{l})$ & 5.4 & 0.2 & $4.86-5.65$ \\
\hline F1 (cognitive restraint)* & 4.0 & $2 \cdot 8$ & $0-9$ \\
\hline F2 (disinhibition)* & 3.9 & 1.4 & $1-5$ \\
\hline F3 (hunger)* & 3.5 & $2 \cdot 1$ & $0-8$ \\
\hline Herman Polivy restraint $†$ & $13 \cdot 7$ & 4.5 & $6-20$ \\
\hline
\end{tabular}

${ }^{*} \mathrm{~F} 1-\mathrm{F} 3$ are factors $1-3$ of the three factor eating questionnaire (Stunkard \& Messick, 1985; Westerterp-Plantenga et al. 1999). †Herman Polivy questionnaire (Herman \& Polivy, 1980). consent. The study was approved by the Ethical Committee of Maastricht University.

\section{Experimental design}

The experiment had a randomized crossover design. The experimental design consisted of three treatments, each consisting of a 2-week low-energy diet and a subsequent time-blinded test, separated by a 4-week washout period (Kovacs et al. 2001; EMR Kovacs, MS WesterterpPlantenga, WHM Saris, KJ Melanson, I Goossens, P Geurten and F Brouns, unpublished results).

Daily during the treatments, the subjects consumed a lowenergy meal for breakfast, lunch and as an afternoon snack. In addition, for lunch, subjects were allowed to eat a fruit (e.g. apple, pear, orange). For dinner, the subjects ingested a meal of their own choice, but they were instructed to drink no more than one glass of an alcoholic beverage or soft drink. Subjects were instructed to refrain from snacks in between meals. During the day, the subjects were allowed to drink water, coffee and tea (without sugar and milk) ad libitum. The low-energy meal consisted of a semi-solid meal (Milical Crème; Laboratoires Diététique et Santé, Revel, France; $47 \mathrm{~g} / 200 \mathrm{ml}$ water) with or without addition of $2.5 \mathrm{~g}$ modified guar gum (Meyprofin ${ }^{\circledR}$ M-175 (Meyhall AG, Kreuzlingen, Switzerland), a highly purified dietary galactomannan fibre which forms a gel in approximately 5-7 min after adding water) or a solid meal with the same energy density and macronutrient composition (energy $947 \mathrm{~kJ}$, protein $17.9 \mathrm{~g}$, carbohydrate $21.0 \mathrm{~g}$, fat $7.9 \mathrm{~g}$ ). The semi-solid meal was offered in three flavours (vanilla, chocolate, caramel) and the subjects were allowed to choose the meals in the flavours they preferred. The solid meal was prepared by the subjects themselves using our specific instructions. Compliance to the dietary instructions was controlled using food intake diaries (Kovacs et al. 2001).

At the end of each intervention, the subjects reported to the laboratory between 08.00 and 09.00 hours, following a $10 \mathrm{~h}$ overnight fast, for a time-blinded test (EMR Kovacs, MS Westerterp-Plantenga, WHM Saris, KJ Melanson, I Goossens, P Geurten and F Brouns, unpublished results). Testing started at different times that were randomly chosen for the purpose of time blinding. During the test, subjects were housed in a room and isolated from time and food cues to eliminate habitual (time-determined) meal patterns, enabling the investigators to observe meal responses to mainly physiological cues. Television, video, radio, watches and clocks were not in the room, and research staff refrained from making time-related statements. With the exception of the investigators and the subject, no other people were allowed in the room. Subjects sat on a bed and were allowed to read or write during the test. They were not allowed to sleep. Subjects could verbally request a meal (meal initiation) at any time. According to the randomly assigned treatment, subjects consumed, upon the first, second and third meal request (breakfast, lunch and snack respectively), the low-energy meal (semi-solid meal with or without guar gum or solid meal) corresponding to that used during the preceding 2 weeks. During the day, water, coffee and tea (without sugar or milk) were offered ad libitum. Then, upon their fourth meal request (dinner), they ingested a 
standardized meal ad libitum (pasta with tomato sauce). Testing was stopped at the subject's fourth meal request or at 18.00 hours if the subject had not yet requested a third or fourth meal. If the subject requested the third meal after 17.00 hours, testing was stopped at that time point. Upon completion of the testing, subjects were asked to estimate the clock time in order to verify that they were blinded to the time of day.

\section{Measurements}

Anthropometry. Body weight was measured during screening, at the beginning and at the end of each treatment on a digital balance (Seca, model 707; Seca, Hamburg, Germany; weighing accuracy of $0.1 \mathrm{~kg}$ ) with subjects in underwear, in the fasting state, after voiding their bladder. Height was measured during screening using a wallmounted stadiometer (Seca, model 220; Seca). The BMI was calculated as body weight $/ \mathrm{height}^{2}\left(\mathrm{~kg} / \mathrm{m}^{2}\right)$. The fat distribution was determined during screening by measuring the waist and hip circumferences and calculation of the waist:hip ratio. The waist circumference was measured at the site of the smallest circumference between the rib cage and the iliac crest, with the subjects standing. The hip circumference was measured at the site of the largest circumference between the waist and the thighs. The waist:hip ratio was calculated by dividing the waist circumference by the hip circumference. Body composition was measured at baseline by using the ${ }^{2} \mathrm{H}_{2} \mathrm{O}$ dilution technique (Schoeller et al. 1980). The dilution of the ${ }^{2} \mathrm{H}$ isotope is a measure for total body water (van Marken Lichtenbelt et al. 1994). Subjects were asked to collect a urine sample in the evening just before drinking a weighed amount of ${ }^{2} \mathrm{H}$-enriched water. After ingestion of the ${ }^{2} \mathrm{H}$-enriched water, no further fluid or food consumption was permitted. Ten hours later a second urine sample (second voiding) was collected. ${ }^{2} \mathrm{H}$ concentration in the urine samples was measured using an isotope-ratio MS (Micromass Optima, Manchester, UK). Total body water was obtained by dividing the measured ${ }^{2} \mathrm{H}$ dilution space by 1.04 (Schoeller et al. 1980). Fat-free mass was calculated by dividing the total body water by the hydration factor 0.73 . By subtracting fat-free mass from body weight, fat mass was obtained. Fat mass expressed as a percentage of body weight revealed percentage body fat.

Attitude towards eating. Attitude towards eating with regard to dietary restraint was determined using a validated Dutch translation of the three-factor eating questionnaire (Stunkard \& Messick, 1985; Westerterp-Plantenga et al. 1999). Cognitive restrained and unrestrained eating behaviour (factor 1), emotional eating and disinhibition (factor 2) and the subjective feeling of hunger (factor 3) were scored. Body weight concern and chronic dieting behaviour were investigated with the Herman Polivy questionnaire (Herman \& Polivy, 1980).

Blood variables. Systolic and diastolic blood pressures were measured during screening by an automatic blood pressure monitor (Omron $705 \mathrm{CP}$; Omron Healthcare $\mathrm{GmbH}$, Hamburg, Germany). A fasting blood sample (2 ml) was obtained and mixed with EDTA to prevent clotting. Plasma was obtained by centrifugation and then stored at $-20^{\circ} \mathrm{C}$ until analysis for glucose by a hexokinase method (Cobas Bio; ${ }^{\circledR}$ Roche Diagnostics, Hoffmann-La Roche, Basel, Switzerland).

On-line blood glucose monitoring. After the subject was comfortably settled, an 18 -gauge, $5 \mathrm{~cm}$ angiocath was placed in the antecubital vein of the non-dominant arm. The blood withdrawal end of a specially modified, $2.5 \mathrm{~m}$ long double-lumen catheter (MTB Medizintechnik, Amstetten, Germany) was fitted into the angiocath. The catheter was continuously heparinized by pumping a sterile heparinsaline solution $(500-5000 \mathrm{U} / \mathrm{ml})$ at a rate of approximately $25 \mu \mathrm{l} / \mathrm{min}$ through the distal lumen of the catheter to the tip of the cannula. The blood and heparin-saline solution mixture was continuously withdrawn through the proximal lumen of the cannula at a rate of approximately $50 \mu \mathrm{l} / \mathrm{min}$ (blood withdrawal rate $25 \mu \mathrm{l} / \mathrm{min}$ ). The blood and heparinsaline solution mixture was mixed with a heparinized phosphate buffer, $(1: 10, \mathrm{v} / \mathrm{v})$, and continuously infused into a sample chamber of a glucose analyser (Model 23A; Yellow Springs Instrument Co., Yellow Springs, OH, USA). Approximately $15 \mathrm{ml}$ blood were withdrawn on the testing day. The transit time of this continuous sampling was approximately $4 \mathrm{~min}$, which was timed for each catheter, and accounted for in the data analysis. Sampling occurred at a rate of ten times per min, and analogue data were amplified, digitized, interfaced (HP 34401 A Digital Multimeter; Hewlett Packard, Palo Alto, CA, USA), and displayed continuously on a computer monitor. This monitor was not visible to the subjects. For $30 \mathrm{~min}$ prior to the insertion of the catheter into the subjects, and following the completion of testing, the system was calibrated using a bag of sterile saline with a known concentration of glucose added. This calibration was done using the same blood-withdrawal cannula that was used in the subject that day (Melanson et al. 1999a,b,c).

\section{Statistics}

Data are presented as mean values with their standard errors. Differences between treatments were determined by ANOVA for repeated measures and Sheffe-F post-hoc test (Statview $^{\text {TM }}$ SE+ Graphics 1988; Abacus Concepts, Berkeley, CA, USA). The level of significance was set at $P<0.05$.

One min averages of blood glucose concentrations over time were plotted for each subject's test day. The data set was corrected by the exact transit time of the catheter used for sampling. An analysis program was written to determine whenever there was a period of stable baseline glucose $(\mathrm{SD}<0.055 \mathrm{mmol} / \mathrm{l})$ that lasted $5 \mathrm{~min}$ or longer. Transient declines in blood glucose have been defined as a decrease of at least $5 \%$ below a stable baseline glucose level (SD $>0.111 \mathrm{mmol} / \mathrm{l}$ ) for at least $5 \mathrm{~min}$ (Campfield et al. 1985, 1996; Campfield \& Smith, 1990b). Dynamic declines in blood glucose were defined as rapid declines which did not originate from a stable baseline, but rather from a peak induced by nutrient ingestion (Melanson et al. 1999c). Transient and dynamic declines were tallied for each test day, and the number of times that meal initiation occurred in the presence or absence of a blood glucose decline was quantified. Postabsorptive refers to the state when all the 
previously ingested food has been absorbed from the digestive tract, whereas postprandial refers to the state when the digestive tract contains ingested food. Since in the present study, testing started at least $10 \mathrm{~h}$ after the last nutrient ingestion, the postabsorptive state was defined as the period from the beginning of testing until the first meal consumption. The postprandial state was defined as the period from the first meal consumption until the end of testing. Associations between meal initiations and changes in blood glucose were tested using the $\chi^{2}$ test for $2 \times 2$ contingency tables with correction for continuity (Parker, 1986).

\section{Results}

The subjects were in negative energy balance during the time-blinded test. Body weight loss during 2-week treatment was 2.5 (SE 0.4) kg, 1.8 (SE 0.3) $\mathrm{kg}$ and 1.8 (SE $0 \cdot 4) \mathrm{kg}$ during semi-solid meal with guar gum, semi-solid meal without guar gum and solid meal respectively and not significantly different between treatments. During the first trial, body weight loss was greater than during the second and the third trial $(2.9(\mathrm{SE} 0.3) \mathrm{kg}, 1.9(\mathrm{SE} 0 \cdot 3) \mathrm{kg}$ and 1.3 (SE $0 \cdot 3) \mathrm{kg}$, respectively; $P<0 \cdot 001)$. There was no difference in body weight loss between treatments during the first, the second or the third trial. Mean body weight regain was 0.6 (SE 0.4) kg during washout from the first to the second trial and 0.6 (SE 0.3) kg during washout from the second to the third trial. This is 20 and $32 \%$ of body weight lost during the previous trial respectively.

During each test two to four spontaneous meal initiations occurred, but there was no difference in the number of meal initiations between treatments (semi-solid meal with guar gum $3 \cdot 1$ (SE 0.2), semi-solid meal without guar gum $3 \cdot 2$ (SE $0 \cdot 2)$; solid meal $3 \cdot 0(\operatorname{SE} 0 \cdot 2)$ ).

The subject's estimation of clock time at the end of the testing day ranged from -96 to $+198 \mathrm{~min}$, verifying that the subjects were blinded to the time of day.

From the total of forty-five testing days, forty blood glucose curves were complete to be used for calculations. The other five blood glucose curves were stopped early because of occlusion of the catheter by clotting and were therefore not used for calculation. Examples of glucose curves are depicted in Fig. 1. There were no significant differences among the three treatments in the number of postabsorptive and postprandial declines in blood glucose or in associations between meal initiations and blood glucose dynamics (Table 2). Moreover there were no significant treatment differences in baseline blood glucose measured by on-line blood glucose monitoring, plasma glucose, insulin,
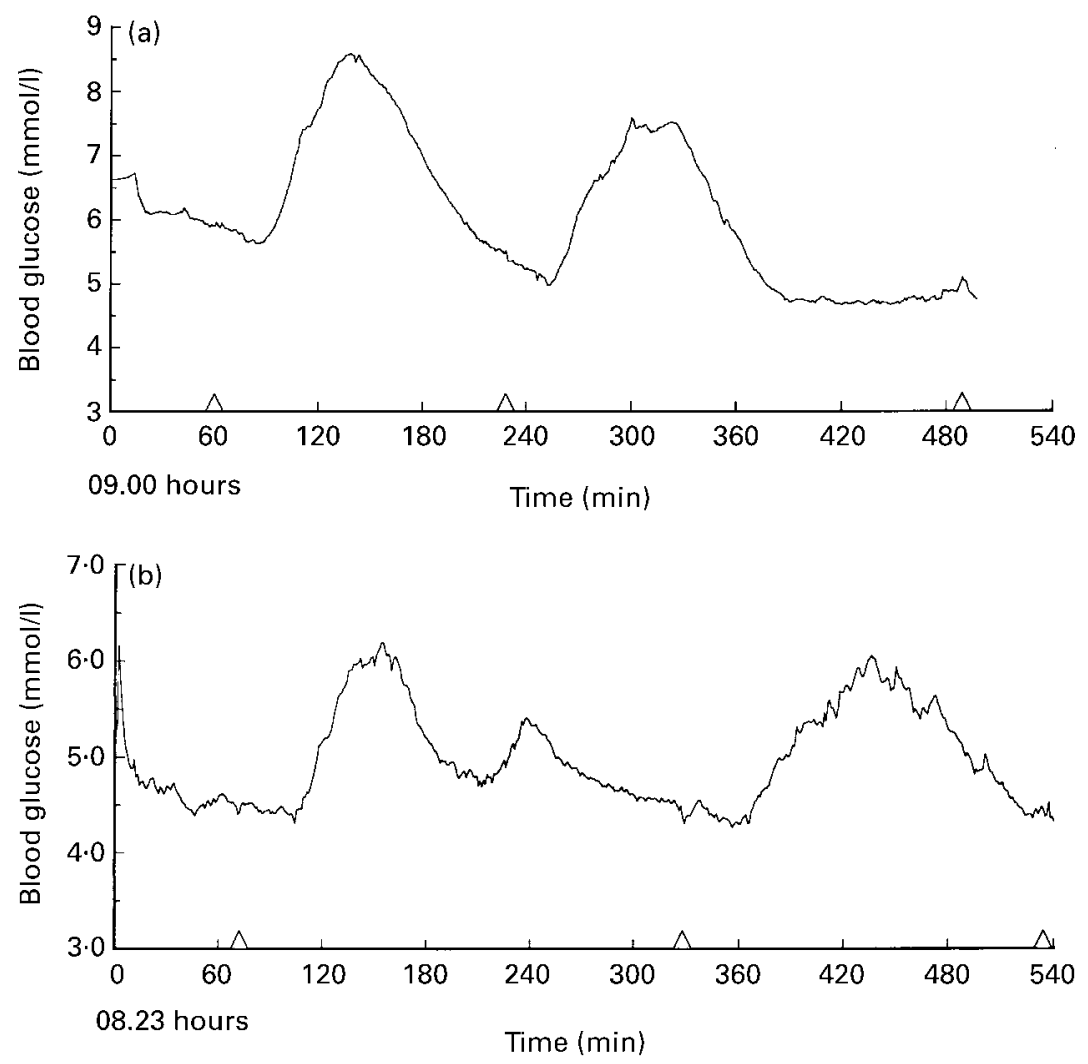

Fig. 1. Blood glucose profiles of two subjects during testing with solid meals. For details of test meals and procedures, see p. 40. $\Delta$, Initiation of meal. In both cases, the first meal was initiated in the absence of a transient decline. (a) The second meal occurred in association with a postprandial transient decline and the third meal was initiated at the nadir of a dynamic decline. (b) The second meal was initiated at the nadir of a dynamic decline and the third meal occurred during a period of relative stable blood glucose after a dynamic decline. 
Table 2. Responses observed in relationship between blood glucose patterns and spontaneous meal initiations for each treatment*

\begin{tabular}{|c|c|c|c|c|c|c|}
\hline & \multicolumn{3}{|c|}{$\begin{array}{l}\text { Declines in blood } \\
\text { glucose associated } \\
\text { with meal initiations }\end{array}$} & \multicolumn{3}{|c|}{$\begin{array}{l}\text { Meal initiations } \\
\text { associated with } \\
\text { declines in blood } \\
\text { glucose }\end{array}$} \\
\hline & Yes & No & Total & Yes & No & Total \\
\hline \multicolumn{7}{|c|}{ Semi-solid meal with guar gum } \\
\hline Postabsorptive transient & 0 & 0 & 0 & 0 & 13 & 13 \\
\hline Postprandial transient & 2 & 0 & 2 & 2 & 11 & 13 \\
\hline Postprandial dynamic & 13 & 15 & 28 & 13 & 0 & 13 \\
\hline \multicolumn{7}{|c|}{ Semi-solid meal without guar gum } \\
\hline Postabsorptive transient & 0 & 0 & 0 & 0 & 14 & 14 \\
\hline Postprandial transient & 1 & 0 & 1 & 1 & 12 & 13 \\
\hline Postprandial dynamic & 15 & 17 & 32 & 15 & 0 & 15 \\
\hline \multicolumn{7}{|l|}{ Solid meal } \\
\hline Postabsorptive transient & 0 & 0 & 0 & 0 & 13 & 13 \\
\hline Postprandial transient & 1 & 0 & 1 & 1 & 10 & 11 \\
\hline Postprandial dynamic & 13 & 13 & 26 & 13 & 0 & 13 \\
\hline
\end{tabular}

${ }^{*}$ For details of subjects, test meals and procedures, see Table 1 and p. 40.

free fatty acids, glycerol, $\beta$-hydroxybutyrate and RER (EMR Kovacs, MS Westerterp-Plantenga, WHM Saris, KJ Melanson, I Goossens, P Geurten and F Brouns, unpublished results). Therefore, the results for semi-solid meal with guar gum, semi-solid meal without guar gum and solid meal were pooled for further analysis. In the postabsorptive state, no transient declines occurred. The forty meal initiations in the postabsorptive state were not associated with changes in blood glucose patterns (Table 3). In the postprandial state, eighty-six dynamic declines occurred and spontaneous meal initiation occurred during forty-one (48\%) of these declines (Table 3). Moreover, in the postprandial state, four transient declines occurred, all associated with spontaneous meal initiation (Table 3). Finally, in the postprandial state, thirty-three more meals occurred in the absence of blood glucose declines (Table 3 ). Thus, blood glucose declines only occurred in the postabsorptive state and were associated with meal initiations in $50 \%$ of the total number of cases. In the postabsorptive state, meal initiations always occurred in the absence of blood glucose declines. In the postprandial state, $58 \%$ of the meal initiations occurred in the presence of blood glucose declines. Only the association between meal initiations and postprandial dynamic declines was statistically significant $(P<0 \cdot 001$; Table 3$)$.

\section{Discussion}

In the present study, transient declines in blood glucose were completely absent in the postabsorptive state in overweight men who were in a negative energy balance. This is in contrast to earlier studies with similar experimental conditions in which postabsorptive transient declines in blood glucose were highly associated with spontaneous meal initiations in human subjects who were in energy balance (Campfield et al. 1996; Melanson et al. $1999 a, c$ ) and in rats (Louis-Sylvestre \& Le Magnen, 1980; Campfield et al. 1985). Campfield \& Smith (1990b) have proposed that it is the pattern of blood glucose over time, i.e. the transient decline in blood glucose, rather than glucose concentration per se that signals meal initiation, indicating a need for fuel ingestion to the organism. However, the findings of the present study are more in line with the results of a recent study in which it was observed that postabsorptive transient declines in blood glucose are infrequent in glycogen-depleted lean subjects (Melanson

Table 3. Responses observed in relationship between blood glucose patterns and spontaneous meal initiations for all treatments combined ${ }^{\star} \dagger$

\begin{tabular}{|c|c|c|c|c|c|c|c|c|c|c|}
\hline & \multicolumn{5}{|c|}{$\begin{array}{l}\text { Declines in blood glucose associated } \\
\text { with meal initiations }\end{array}$} & \multicolumn{5}{|c|}{$\begin{array}{l}\text { Meal initiations associated with declines } \\
\text { in blood glucose }\end{array}$} \\
\hline & \multicolumn{2}{|c|}{ Yes } & \multicolumn{2}{|c|}{ No } & \multirow[b]{2}{*}{ Total $(n)$} & \multicolumn{2}{|c|}{ Yes } & \multicolumn{2}{|c|}{ No } & \multirow[b]{2}{*}{ Total $(n)$} \\
\hline & $n$ & $\%$ & $n$ & $\%$ & & $n$ & $\%$ & $n$ & $\%$ & \\
\hline Postabsorptive transientł & 0 & - & 0 & - & 0 & 0 & 0 & 40 & 100 & 40 \\
\hline Postprandial transient§ & 4 & 100 & 0 & 0 & 4 & 4 & 11 & 33 & 89 & 37 \\
\hline Postprandial dynamic $\|$ & 41 & 48 & 44 & 52 & 86 & 41 & 100 & 0 & 0 & 41 \\
\hline
\end{tabular}

${ }^{*}$ For details of subjects, test meals and procedures, see Table 1 and p. 40.

$\dagger \rightarrow 40$ testing days.

Association between meal initiations and blood glucose declines was determined using the $\chi^{2}$ test: $\ddagger \chi^{2}$ error; $\S \chi^{2} 2.63, P>0.1 ; \| \chi^{2}$ 26.8, $P<0.001$ 
et al. 1999b). In that study, spontaneous meal initiation occurred in the absence of such declines, and it was thus suggested to be associated with deprivation-induced feeding. In the present study, a first explanation for the absence of transient declines in the postabsorptive state may be that subjects were in a negative energy balance. During the 2 weeks prior to testing they consumed $3 \cdot 6-4 \cdot 0 \mathrm{MJ} / \mathrm{d}$ less than during a normal situation (Kovacs et al. 2001). Carbohydrate intake was also diminished and subjects were in a negative carbohydrate balance. The absence of postabsorptive transient declines in blood glucose may therefore be explained by decreased substrate availability. In this respect, decreased substrate availability after 2 weeks of the low-energy diet was shown by a relatively high concentration of plasma free fatty acids (mean for the three treatments $408 \mu \mathrm{mol} / \mathrm{l}$ ) and a relatively low RER (approximately 0.79 ) in the fasting state (EMR Kovacs, MS Westerterp-Plantenga, WHM Saris, KJ Melanson, I Goossens, P Geurten and F Brouns, unpublished results), similar to the findings of Melanson et al. (1999b) in glycogen-depleted lean subjects. Moreover, increased hepatic fatty acid oxidation was indicated by a relatively high concentration of fasting plasma $\beta$-hydroxybutyrate (mean for the three treatments $258 \mathrm{mmol} / \mathrm{l}$; EMR Kovacs, MS Westerterp-Plantenga, WHM Saris, KJ Melanson, I Goossens, P Geurten and F Brouns, unpublished results). In this regard, fatty acid oxidation is associated with decreased hunger and reduced food intake (Langhans, 1999). Baseline blood glucose levels measured by on-line blood glucose monitoring $(4.8 \mathrm{mmol} / \mathrm{l})$ were similar to the levels measured in lean subjects in stable energy balance $(4.5 \mathrm{mmol} / \mathrm{l}$; Melanson et al. 1999a,c), indicating that mechanisms are activated in order to maintain glycaemia to a normal level during negative energy balance. Hepatic fatty acid oxidation fuels gluconeogenesis, and a constantly high level of gluconeogenesis in negative energy balance may be a reason for the absence of postabsorptive transient declines in blood glucose. A second explanation for the absence of transient declines in the postabsorptive state may be that subjects were overweight, therefore having a less pronounced food intake regulation and blood glucose response compared with young lean male subjects (Björntorp, 1972). Further research is needed to assess whether the absence of postabsorptive transient declines is due to the energy balance state (negative $v$. positive energy balance) or to subject's characteristics (overweight $v$. lean) (Flatt, 1981). If the absence of transient declines is related to a negative energy balance, the relationship between spontaneous meal initiations and transient declines in blood glucose is only present within a normal physiological range of energy (carbohydrate) status.

Postprandially, dynamic declines were associated with spontaneous meal initiations, which has been previously reported (Melanson et al. 1999a,b,c). However, Melanson et al. (1999a,b,c) observed a higher association between meal initiations and postprandial dynamic declines (71$78 \%$ ) compared with the association found in the present study $(48 \%)$. The fact that postprandial dynamic declines initiate only $48 \%$ of meals may indicate that food intake regulation in these subjects is less conditioned by blood glucose response. Postprandially, all transient declines initiated a meal. However, because only few transient declines occurred and because most of the meals were initiated in absence of a transient decline, no association between meal initiation and transient declines was found. This is in contrast to other studies in which spontaneous meal initiations in the postprandial state were associated with transient declines in blood glucose (Melanson et al. 1999a,b,c). Melanson et al. (1999b) observed that transient declines in the postprandial state became apparent and were significantly associated with spontaneous meal initiations, even in glycogen-depleted lean subjects after refeeding with high-carbohydrate or high-fat food and beverages. In the present study, however, the subjects were not only in negative energy balance prior to testing, but they also consumed low-energy meals throughout the day. The resulting low substrate availability and increased hepatic fatty acid oxidation during testing might explain the absence of a relationship between meal initiations and postprandial transient declines. The association between spontaneous meal initiations and transient declines is therefore likely dependent on glycogen stores or postprandially available carbohydrates. Thus, in negative energy balance, the usual relationship between transient declines and spontaneous meal initiations was completely absent also postprandially, indicating a loss of physiological food intake regulation in the overweight while dieting. This might have implications for weight maintenance, in that this can only be achieved by increasing cognitive restraint (Westerterp-Plantenga et al. 1998). Food intake regulation that still was associated with blood glucose patterns consisted of the postprandial association of meal initiations with very rare transient declines and with $48 \%$ of the dynamic declines.

In summary, postprandial dynamic blood glucose declines were significantly associated with meal initiations, but postabsorptive and postprandial transient declines were not. Therefore, we conclude that in overweight subjects, the usual association between transient declines in blood glucose and spontaneous meal initiations was completely absent in negative energy balance.

\section{Acknowledgements}

Supported by Novartis Consumer Health Ltd, Nyon, Switzerland.

\section{References}

Björntorp P (1972) Disturbances in the regulation of food intake. Obesity: anatomic and physiologic-biochemical observations. Advances in Psychosomatic Medicine 7, 116-127.

Campfield LA, Brandon P \& Smith FJ (1985) On-line continuous measurement of blood glucose and meal pattern in free-feeding rats: the role of glucose in meal initiation. Brain Research Bulletin 14, 605-616.

Campfield LA \& Smith FJ (1986) Functional coupling between transient declines in blood glucose and feeding behavior: temporal relationships. Brain Research Bulletin 17, 427-433.

Campfield LA \& Smith FJ (1990a) Transient declines in blood glucose signal meal initiation. International Journal of Obesity 14, 15-33.

Campfield LA \& Smith FJ (1990b) Systemic factors in the control of food intake: evidence for patterns as signals. In Handbook of 
Behavioral Neurobiology: Neurobiology of Food and Fluid Intake, pp. 183-206 [EM Stricker, editor]. New York NY: Plenum Press.

Campfield LA, Smith FJ, Rosenbaum M \& Hirsch J (1996) Human eating: evidence for a physiological basis using a modified paradigm. Neuroscience and Biobehavioral Reviews 20, $133-137$.

Flatt JP (1981) Is food intake regulation based on signals arising in carbohydrate metabolism inherently inadequate for accurate regulation of energy balance on high-fat diets? Behavioral and Brain Sciences 4, 581-583.

Flatt JP (1996) Carbohydrate balance and body weight regulation. Proceedings of the Nutrition Society 55, 449-465.

Herman CP \& Polivy J (1980) Restrained eating. In Obesity, pp. 208-225 [AJ Stunkard, editor]. Philadelphia, PA: W.B. Saunders.

Kovacs EMR, Westerterp-Plantenga MS, Saris WHM, Goossens I, Geurten P \& Brouns F (2001) The effect of addition of modified guar gum to a low-energy semisolid meal on appetite and body weight loss. International Journal of Obesity 25, 307-315.

Langhans W (1999) Metabolic control of food intake. Role of the liver. In Regulation of Food Intake and Energy Expenditure, pp. 185-199 [MS Westerterp-Plantenga, AB Steffens and A Tremblay, editors]. Milano: Edra.

Louis-Sylvestre J \& Le Magnen J (1980) A fall in blood glucose level precedes meal onset in free feeding rats. Neuroscience and Biobehavioral Reviews 4, 13-15.

Mayer J (1953) Glucostatic mechanisms in the regulation of food intake. New England Journal of Medicine 249, 13-16.

Melanson KJ, Westerterp-Plantenga MS, Campfield LA \& Saris WHM (1999a) Blood glucose and meal patterns in time-blinded males, after aspartame, carbohydrate, and fat consumption, in relation to sweetness perception. British Journal of Nutrition 82 , 437-446.

Melanson KJ, Westerterp-Plantenga MS, Campfield LA \& Saris WHM (1999b) Appetite and blood glucose profiles in humans following glycogen-depleting exercise. Journal of Applied Physiology 87, 947-954.
Melanson KJ, Westerterp-Plantenga MS, Smith FJ, Campfield LA \& Saris WHM (1999c) Blood glucose patterns and appetite in time-blinded humans: carbohydrate versus fat. American Journal of Physiology 277, R337-R345.

Parker RE (1986) Introductory Statistics for Biology, pp. 43-54 [E Arnold, editor]. Southampton: The Camelot Press.

Pollack CP, Green J \& Smith GP (1989) Blood glucose prior to meal request in humans isolated from all temporal cues. Physiology and Behavior 49, 529-534.

Schoeller DA, van Santen E, Peterson DW, Diez W, Jaspan J \& Klein PD (1980) Total body water measurement in humans with ${ }^{18} \mathrm{O}$ and ${ }^{2} \mathrm{H}$ labeled water. American Journal of Clinical Nutrition 33, 2686-2693.

Smith FJ \& Campfield LA (1993) Meal initiation occurs after experimental induction of transient declines in blood glucose. American Journal of Physiology 265, R1423-R1429.

Steffens AB (1970) Plasma insulin content in relation to blood glucose level and meal pattern in the normal and hypothalamic hyperphagic rat. Physiology and Behavior 5, 147-151.

Stunkard AJ \& Messick S (1985) The three-factor eating questionnaire to measure dietary restraint, disinhibition, and hunger. Journal of Psychosomatic Research 29, 71-83.

Van Itallie TB (1990) The glucostatic theory 1953-1988: roots and branches. International Journal of Obesity 14, suppl. 3, $1-10$.

van Marken Lichtenbelt WD, Westerterp KR \& Wouters L (1994) Deuterium dilution as a method for determining total body water: effect of test protocol and sampling time. British Journal of Nutrition 72, 491-497.

Westerterp-Plantenga MS, Kempen KPG \& Saris WHM (1998) Determinants of weight maintenance in women after dietinduced weight reduction. International Journal of Obesity 22, $1-6$.

Westerterp-Plantenga MS, Rolland V, Wilson SAJ \& Westerterp KR (1999) Satiety related to $24 \mathrm{~h}$ diet-induced thermogenesis during high protein/carbohydrate vs high fat diets measured in a respiration chamber. European Journal of Clinical Nutrition 53, $1-8$. 